\title{
Preserving reinforced concrete
}

\author{
A. Foster, C. Atkins \& L. Buckley \\ Mott MacDonald, Materials and Corrosion Engineering, UK
}

\begin{abstract}
There is some debate as to when reinforcement was first added into concrete. Most concur that the Parthenon in Rome was fibre reinforced with animal hair almost 2000 years ago. After this, there is a difference of opinion between the French and the British as to the first iron reinforcement in the mid 1800s, with both claiming precedent. The first formally designed systems for reinforced concrete date from the 1900s produced by Hennebique and Mouchel.

Early reinforced concrete structures are now falling within the remit of heritage structures, for example the Liver Building in Liverpool dates back to 1908 and is located on a UNESCO world heritage site. As time passes more and more post war structures are becoming recognised for their uniqueness and achieving protected status. This naturally includes increasingly large numbers of reinforced concrete structures.

This paper discusses the various degradation mechanisms of reinforced concrete and methods of protection available. In addition the sustainability arguments for preserving rather than replacing concrete structures are highlighted, regardless of the aesthetics.

Keywords: reinforced concrete, corrosion, repair, sustainability.
\end{abstract}

\section{Introduction}

Formally designed reinforced concrete structures are part of our heritage, and are becoming recognised as such. However, durability has only been considered as an issue within design codes within the last 30 years (although corrosion of reinforcement was identified as a problem as early as 1910 [1]). The fact that any reinforced concrete structures are durable was not an original design consideration, but more a happy coincidence or side effect. The result of this is that a large number of the reinforced concrete heritage is in an increasingly poor condition. This paper presents a review of the historical systems that were in use, 
along with the durability problems associated both with concrete in general and a number of the specific design systems that were employed. These are illustrated using examples of projects undertaken.

\section{Durability of concrete}

\subsection{Corrosion}

Steel in concrete normally does not corrode. This is more surprising than would be first imagined when it is understood that concrete is a porous material and the steel is sat in a moist environment. The reason it does not corrode in spite of being sat in a moist environment is that when concrete hydrates it produces a very alkaline solution ( $\mathrm{pH}$ in excess of 13). When steel is exposed to an alkaline solution it forms a protective stable oxide film over its surface. This protects the steel from corrosion. There are two basic scenarios where corrosion can occur [2].

\subsubsection{Carbonation}

The atmosphere contains a small amount of carbon dioxide. This can dissolve in moisture to form a mild acid. The mild acid produced reacts with the alkalinity in the concrete and reduces it to a level where corrosion can occur. This process is known as carbonation.

The rate of carbonation depends on the moisture content available. In a dry environment the pores in the concrete are open and the atmosphere can penetrate the concrete more rapidly. This leads to a higher rate of carbonation. However, corrosion needs moisture to occur and so a drier environment may carbonate rapidly but may not result in corrosion. In a very humid environment the pore structure of concrete is blocked with moisture and carbonation takes place more slowly.

\subsubsection{Chlorides}

The other cause of corrosion in concrete is due to chloride ions. When chlorides reach the steel in sufficient quantities they disrupt the passive film and form holes in it. These locations start to corrode.

Chlorides come from a range of sources. In 1888 a patent was filed for adding calcium chloride to concrete to speed up the rate of strength gain. This practice continued in the UK until the mid 1970s when its use was banned due to concerns regarding corrosion. In addition to this marine dredged aggregates were widely used in coastal areas. These contain chlorides from the sea that dried out onto the aggregate. Chlorides from this source are commonly termed 'internal' as they originate from the original mix. When cement hydrates it chemically combines some of the chlorides and stops them participating in the corrosion process. However, as concrete carbonates, some of the chemically combined chlorides are released and can then promote corrosion.

Chlorides can also get into concrete from the external environment. These are known as external chlorides. If a structure is in the vicinity of the sea, then there 
is an obvious source of chloride contamination. Note that wind blown spray can result in chloride contamination a significant distance inland. In addition to this chloride based deicing materials are commonly used.

\subsection{Concrete degradation}

In addition to the reinforcement corrosion the concrete itself can degrade. The commonest causes are sulphate attack or acid attack. In addition to this the aggregate itself can degrade. This can be due to alkali aggregate reaction. In this form of attack the alkali in the cement reacts with the aggregate to produce an expansive gel. This causes the concrete to crack, typically in a three-legged crack form.

\section{Repairing concrete}

In order to repair concrete it is first essential to adequately identify the cause of degradation. Each deterioration mechanism has solutions that suit one cause more than the other. For any damage due to corrosion the likelihood that some concrete repair will be required. The most appropriate method of achieving this is normally to use shrinkage compensated repair mortars. These can either be hand applied for small areas or sprayed back for larger areas. Flowable materials can also be used to reinstate areas but require the manufacture of appropriate formwork.

For carbonation induced corrosion it is possible to allow the alkalinity within the concrete to redistribute by selection of the appropriate coatings. There is increasing evidence that cementitious coatings allow this to take place. This means that corrosion can be relatively straight forward to stop. Typically for carbonation all the steel sat in carbonated concrete is corroding, and so the area that needs to be repaired is easily defined.

For chloride induced corrosion there is no straightforward way of removing the chloride contamination. In addition the areas being damaged are smaller than the extent of corrosion. If the area of damaged concrete is replaced corrosion is likely to initiate in the adjacent areas as they are still chloride contaminated. The act of repair actually makes the corrosion in surrounding areas more aggressive due to an effect known as the incipient anode effect.

In order to perform an effective repair it is therefore either necessary to remove large quantities of contaminated but sound concrete, or to employ more advanced techniques that prevent corrosion occurring. The commonest technique employed is cathodic protection where the area of corrosion is controlled by using low voltage direct current supplied from an external inert material to the steel via a power supply [3].

\section{Sustainability}

An increasing area of concern is energy conservation. As part of this data have been developed that represent the amount of energy that it takes to manufacture, 
transport and assemble materials on site. For every tonne of reinforced concrete produced the cement has to be manufactured from chalk and clay. The coarse and fine aggregates have to be extracted from the ground. The water used in mixing has to be purified to an appropriate quality. The steel has to be manufactured either from raw iron oxide or from scrap metal. This all has to be transported to its final resting place, mixed and assembled. This all takes energy, which is known as embodied energy. The table below shows figures for typical materials.

Once a structure has been built the embodied energy reaches a constant figure. However, once it begins to degrade this embodied energy starts to be lost. If a repair is necessary additional materials will be required, introducing additional embodied energy. Any repair will require the removal and disposal of defective material. After this, reinstatement will be required. This adds to the embodied energy within the structure. It can therefore simply be argued that from a sustainability point of view it is therefore better to preserve. If it is too late to preserve it is better to minimise the extent of repairs.

Table 1: $\quad$ Embodied energy of common structural materials [4].

\begin{tabular}{|l|c|}
\hline \multicolumn{1}{|c|}{ MATERIAL } & GJ/tonne \\
\hline \hline Wood & $0.5-3.5$ \\
\hline \hline MDF & 11 \\
\hline \hline Plywood & 10 \\
\hline \hline Polymers & 90 \\
\hline Plasterboard & 4.5 \\
\hline \hline Cement & 5.5 \\
\hline In-Situ Concrete & 2.5 \\
\hline \hline Steel Reinforcement & 40 \\
\hline Aluminium & 170 \\
\hline
\end{tabular}




\section{Project examples}

\subsection{Beehive Mill}

The early use of concrete in connection with steel was in the form of a filler joist floor. Concrete was used to form the infill between beams. The material comprised a cementitious material used to bind a selection of aggregate that ranged from coke breeze to broken brick. The resultant concrete is very porous and the aggregate used is often contaminated with corrosion promoting products such as sulphur compounds.

The major industry of Lancashire, England was cotton and a great many cotton mills were constructed using a variety of cast iron, wrought iron or steel columns and beams, including filler joist floor construction. When the industry collapsed a large number of these were purchased at a low cost and used for warehousing and storage. Beehive Mill in Bolton is typical of this type of structure. One area of the factory was over a basement that was previously used to store the cotton bales in a moist environment. The floor loading in this area prevented the use of Fork Lift trucks and limited the storage capacity, so the client was looking to enhance the load capacity of the floor to permit more of the floor space for use as storage.

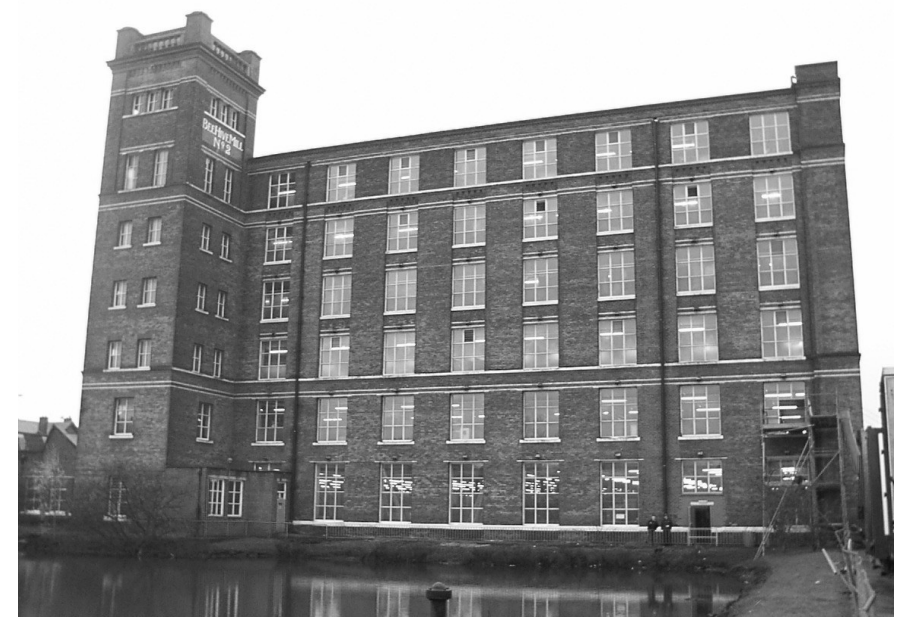

Figure 1: $\quad$ Beehive Mill.

An initial inspection identified that the corrosion was being caused by carbonation of the fill material, combined with the presence of aggressive chemicals within the fill. It was decided to employ a cathodic protection system to prevent corrosion of the filler joists and embedded beams. Carbon fibre plates were used to enhance the structural capacity of the floor. Carbon fibre plates were selected as the strengthening measure for ease of handling as all access to 
the basement was via a domestic door. $2.4 \mathrm{~mm}$ thick plates were applied to the soffit of each beam.

The cathodic protection system was developed using mixed metal oxide coated titanium ribbon installed in $5 \mathrm{~mm}$ thick chases cut directly into the existing concrete between the joists. The titanium ribbon was embedded into the chases and then backfilled.

Overall the system was split into two independently controlled areas and monitored using embedded silver/silver chloride reference electrodes. The system was successfully energised at a low current density and achieved protection in accordance with the international standards.

\subsection{Thorverton Bridge}

This bridge is the main access to a small village in Devon in the south west of England. It dates from 1908 and is the oldest reinforced concrete bridge in Devon. Significant corrosion was identified due to carbonation of the concrete. Little chloride contamination was found in spite of the fact the structure had been regularly deiced using chloride based deicing salts. In addition to this the structure had been identified as understrength under the 40 tonne assessment programme and therefore required strengthening.

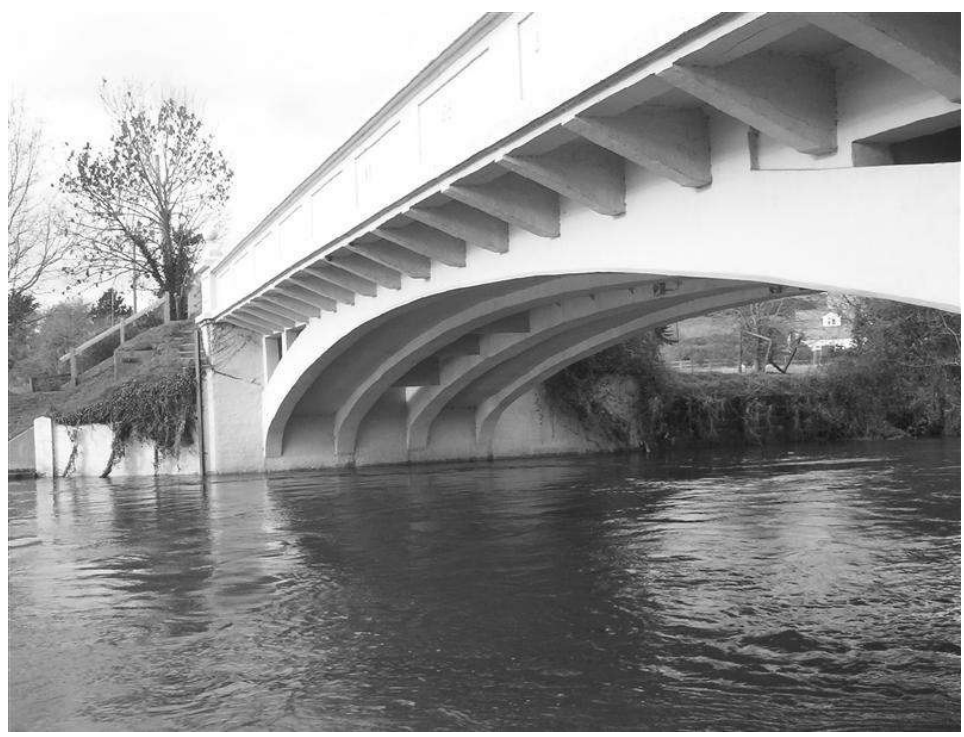

Figure 2: $\quad$ Thorverton Bridge.

The solution developed was based on casting additional concrete arches between the existing arches. A cathodic protection system was installed to ensure durability. The cathodic protection was based on discrete anodes comprising a coated titanium rod inserted into a carbonaceous gel. These anodes were up to 
$0.5 \mathrm{~m}$ long and were interlinked using titanium wire back to a central power and control unit. The monitoring system was routed back to a remote system that could be monitored and adjusted via a telephone system.

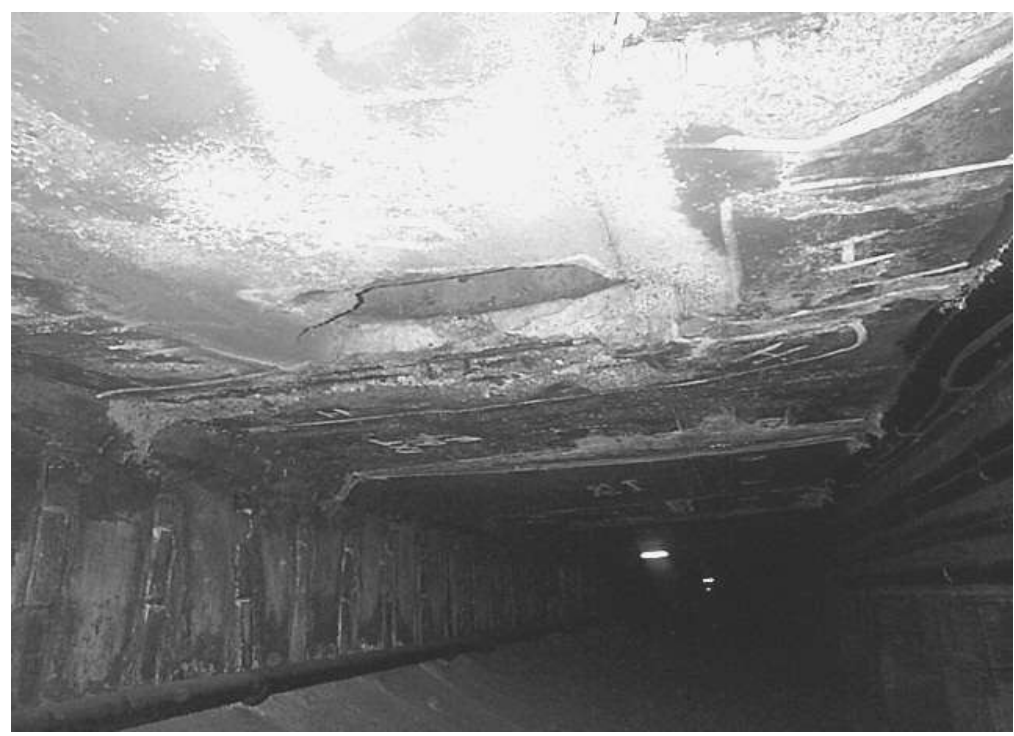

Figure 3: $\quad$ Soffit degradation prior to repair at Queensway Tunnel.

\subsection{Queensway tunnel deck}

The Queensway tunnel joins Liverpool to Birkenhead in the North West of England. It was designed by Sir Basil Mott and construction started in 1925. The design of the deck is a Hennebique based system. In this system the reinforcement starts in the top of the deck by the supports then cranks into the soffit of the deck across the mid span. At the time of construction cover to the reinforcement was considered a fire protection issue only with no regard to durability and so the steel is relatively close to the surface of the concrete.

Unusually for a tunnel the deck runs at the mid point of the bore as it was originally intended to have car traffic above the deck and a light rail system running under the deck. Ultimately the light rail system was prevented due to opposition from the local ferry companies, but the underside of the deck was used as part of the ventilation system.

After a routine inspection significant corrosion of the deck soffit was identified. This was due to carbonation, accelerated by the dry air being constantly blown over the surface of the concrete. Chloride testing was undertaken on the top of the deck and significant chloride was identified throughout the tunnel, despite the fact that the tunnel had never been deiced. This was attributed to vehicular traffic tracking chlorides in from the surrounding area. 
The repair procedure was complicated by the access. Whilst there was plenty of room under the main bore, in order to get to this area entry and exit was via small passages. Based on the difficulties in accessing the job the repair process was developed using ultra high water pressure jetting to remove all loose and delaminated concrete, and dry sprayed concrete to reinstate the removed concrete. All spoil had to be removed and all materials had to be brought to the area of work via the same limited access points.

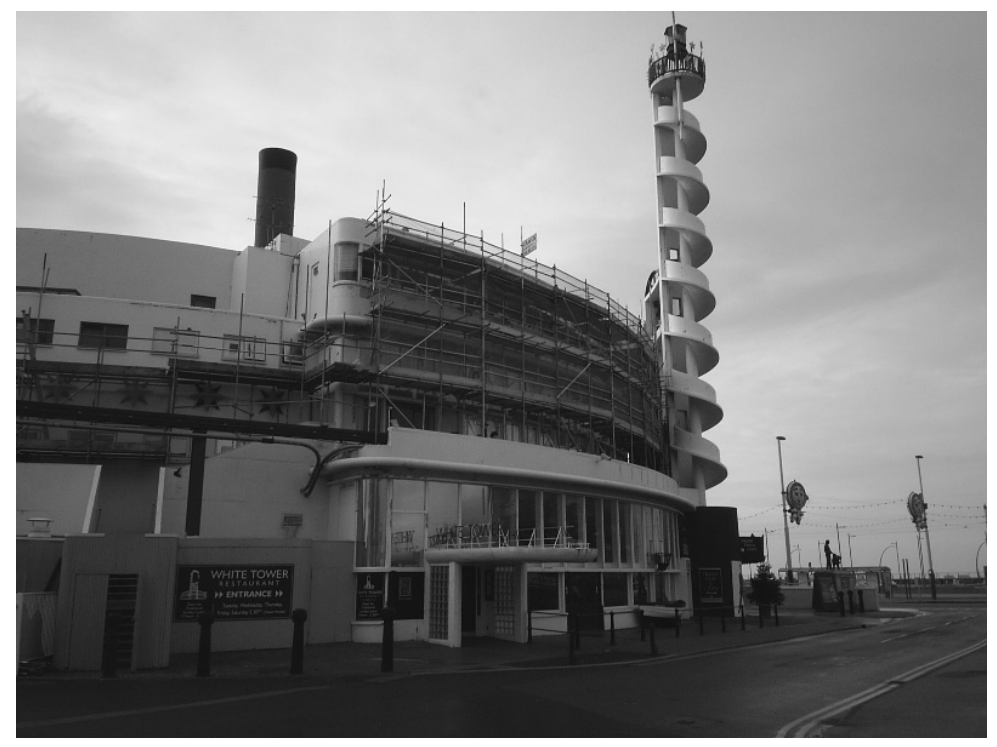

Figure 4: White Tower prior to completion of repairs.

These repairs were reviewed as part of a recent project to investigate successful concrete repairs by the Health and Safety Executive and found to be performing adequately.

\subsection{White Tower, Blackpool}

The White Tower building in Blackpool is a fine example of Art Deco style. The building was constructed in 1939. The external envelope was originally made up of white Portland cement with a quartz aggregate. Over the years it had succumbed to extensive chloride contamination. In addition it had been coated and patch repaired many times. In 2005 a $£ 500,000$ repair project was undertaken. Due to the extent of degradation and previous repairs it was not possible to restore the original finish to the structure as little of it remained.

One further problem was that in some of the larger elements the exterior façade was made up using permanent formwork to achieve the high quality finish. The reinforcement was placed in the formwork and backfilled with conventional concrete, in a procedure similar to that used by Frank Lloyd 
Wright. This gives the initial impression of a high quality finish, however the concrete behind the façade is of poor quality, heavily voided and rapidly degrades.

The repair procedure involved the removal of all loose and delaminated concrete and reinstatement with appropriate repair materials. In spite of the benefits that cathodic protection normally provides in minimising the extent of breakout, it was not appropriate for this structure as the façade was made up of many individual precast elements. This would have required a very complex $\mathrm{CP}$ system which would have precluded the repair contract. Once the repairs were completed the whole structure was recoated [5]. The structure owner has introduced a rolling programme of inspections to enable the maintenance of the building to be better planned.

\section{Summary}

A significant number of reinforced concrete structures have now been around for a sufficient length of time to become part of our heritage. Their preservation is not only in the interests of conservation, but is also the best way of minimizing the environmental impact of construction and thereby contributing to sustainability.

A range of repair procedures and specialist materials and techniques have been developed, particularly over the last decade, that can reinstate or enhance the durability and performance of existing reinforced concrete structures while allowing the original structure to remain relatively intact.

By applying such techniques it should be possible to ensure that the best and most representative reinforced concrete from the last century can be made available as viable working structures for the functional and aesthetic benefit of future generations.

\section{References}

[1] Institution of Civil Engineers Preliminary and Interim Report of the Committee on Reinforced Concrete, Pub The Institution, London 1910.

[2] Lambert, P, 'Corrosion mechanisms - an introduction to aqueous corrosion', Corrosion Prevention Association, Technical Note No.5, 2001.

[3] Broomfield, J P \& Wyatt, B S, 'Cathodic protection of steel in concrete - the international perspective', Corrosion Prevention Association, Technical Note No.3, 2002.

[4] Atkins C P, Buckley L \& Lambert P, 'Sustainability \& repair', Concrete Communications Conference, UCL/The Concrete Society, September 2006.

[5] Atkins C P, 'Long term performance of concrete coatings - a case study', Corrosion Management, pp 18-21, October 2004. 